\title{
Moderating Material to Compensate the Drawback of High Minor Actinide Containing Transmutation Fuel on the Feedback Effects in SFR Cores
}

\author{
Bruno Merk \\ Department of Reactor Safety, Institute of Resource Ecology, Helmholtz-Zentrum Dresden-Rossendorf, Postfach 510119 , \\ 01314 Dresden, Germany \\ Correspondence should be addressed to Bruno Merk; b.merk@hzdr.de
}

Received 4 September 2012; Accepted 4 February 2013

Academic Editor: Wei Shen

Copyright (C) 2013 Bruno Merk. This is an open access article distributed under the Creative Commons Attribution License, which permits unrestricted use, distribution, and reproduction in any medium, provided the original work is properly cited.

\begin{abstract}
The use of fine distributed moderating material to enhance the feedback effects and to reduce the sodium void effecting SFRs is described. The drawback on the feedback effects due to the introduction of minor actinides into SFR fuel is analyzed. The possibility of compensation of the effect of the minor actinides on the feedback effects by the use of fine distributed moderating material is demonstrated. The consequences of the introduction of fine distributed moderating material into fuel assemblies with fuel configurations foreseen for minor actinide transmutation are analyzed, and the positive effects on the transmutation efficiency are shown. Finally, the possible increase of the Americium content to improve the transmutation efficiency is discussed, the limit value of Americium is determined, and the possibilities given by an increase of the hydrogen content are analyzed.
\end{abstract}

\section{Introduction}

The positive coolant density feedback coefficient is inherent to the system in sodium-cooled fast reactors (SFRs). This effect is the basis for the sodium void effect, which is the maximal reduction of the sodium density. The reduction of the positive feedback effects as well as the enhancement of the negative ones is an important point in the design of future sodium-cooled fast reactors. The relevance of the topic has been highlighted in the last year in the IAEA TM on Innovative Fast Reactor Designs with Enhanced Negative Reactivity Feedback Features in Vienna [1].

The nature of feedback effects in fast reactors as well as the sodium void effect itself and the different contributions to the effect are well known since the 1960s. Detailed descriptions have already been given in "Reactivity Coefficients in Large Fast Power Reactors" in 1970 [2]. Already in the 1970s numerical studies were performed with the aim to reduce the sodium void effect [3]. These studies were mostly performed on the basis of full core calculations for the optimization of the core geometry to reduce the sodium void effect.
One important outcome of the full core calculations was the development of high leakage cores with their big core diameter ( $\sim 5$ meters $)$ in combination with a very small core height $(\leq 1$ meter). Another method for the enhancement of the leakage in the case of sodium voiding is the replacement of the reflector above the core with a sodium plenum which enhances the leakage significantly in the case of a sodium voiding event in the upper core region. Current publications mostly concentrate on the design of sodium-cooled fast reactor cores [4], on advanced safety concepts for SFR [5], and on basic or detailed discussions on the different influencing parameters on the sodium void coefficient $[6,7]$ and the limited possibilities for enhancing the feedback effects in traditional designs.

Recently, a new proposal has been published. The positive void effect is reduced here in combination with a significant enhancement of the negative fuel temperature effect and a decrease of the positive coolant effect by adding fine distributed moderating material. The study has been focused in the first step on the choice of the ideal moderating material $[8,9]$ and in a second step on the optimization of the placing 
of the zirconium hydride to obtain the optimal effect in power distribution and burnup $[10,11]$ to limit the required changes in the fuel assembly and in the core design.

The calculations are performed with the lattice transport code HELIOS and based detailed full fuel assembly geometry representation. These possibilities are given due to the rapid development of the spectral codes for LWR analysis which solve the integral transport equation in two dimensions on unstructured mesh $[12,13]$. These codes offer the chance to investigate the feedback effects on fuel assembly level for different designs in full detail including multigroup visualization of integral and resolved neutron flux and cross sections. The verification of the results for the enhanced feedback effects calculated with HELIOS has been performed by a comparison calculation using MCNP $5[8,9]$.

The insertion of moderating material softens the neutron spectrum of the fast reactor. Nevertheless, for the burning of minor actinides, a hard neutron spectrum is essential due to the fission threshold of these isotopes. Following this knowledge, the effect of the use of a small, fine distributed amount of moderating material on the efficiency of minor actinide burning will be investigated in this publication.

\section{Reference System}

For the beginning of the study, a reference case based on the European Fast Reactor is defined (see Figure 1). The data is mostly given in the IAEA Fast Reactor Database2006 Update [14]. Additional data is taken from Waltar, Reynolds: Fast Breeder Reactors [15] and from European fast reactor (EFR) fuel element design [16]. The following major parameters are used: outer pin diameter $8.5 \mathrm{~mm}$, cladding thickness $0.52 \mathrm{~mm}$, pitch to diameter 1.2 , can wall thickness $4.5 \mathrm{~mm}$, wire spacers, and 271 fuel rods per element.

Materials. MOX Fuel with 22.4\% $\mathrm{Pu}$ fissile and $\mathrm{Pu}$ vector from $4 \%$ enriched LWR fuel with $50 \mathrm{GWd} / \mathrm{tHM}$ burnup. 5year storage is estimated before reprocessing and 2 years until reuse in the reactor. The $\mathrm{Pu}$-Vektor is $(2.6 / 54.5 / 23.7 / 11.3 / 6.8)$ and $1.1 \%$ Am-241 in depleted uranium (0.3\% U-235 content). The smeared fuel density is $9.26 \mathrm{~g} / \mathrm{cm}^{3}$, and the fuel temperature is $900^{\circ} \mathrm{C}$. Cladding, wire spacers, and can wall are made from stainless steel 304 along the HELIOS 1.9 definition. The temperatures are $635^{\circ} \mathrm{C}$ for the cladding and $545^{\circ} \mathrm{C}$ for wire spacer and can wall. Sodium density is $0.821 \mathrm{~g} / \mathrm{cm}^{3}$ along the formula for liquid saturated sodium at $545^{\circ} \mathrm{C}$ given in Waltar and Reynolds [15]. The geometric arrangement of the reference system with 10 rings is shown in Figure 1 for 1/6 part of one fuel element. The used power density is $118.8 \mathrm{~W} / \mathrm{g}$ corresponding to the maximum power density in the EFR. For the calculation HELIOS is used. The internal 112 group fast reactor cross-section library of Studsvik Scandpower is used for the investigation. Only for the calculations of the neutron spectrum the 190 energy group library is used to have a refined energy structure in the thermal range for a better depiction.

Three different minor actinide loadings will be investigated (3\% Am, 5\% Am, and 2\% Np-2\% Am) [17]. The Am

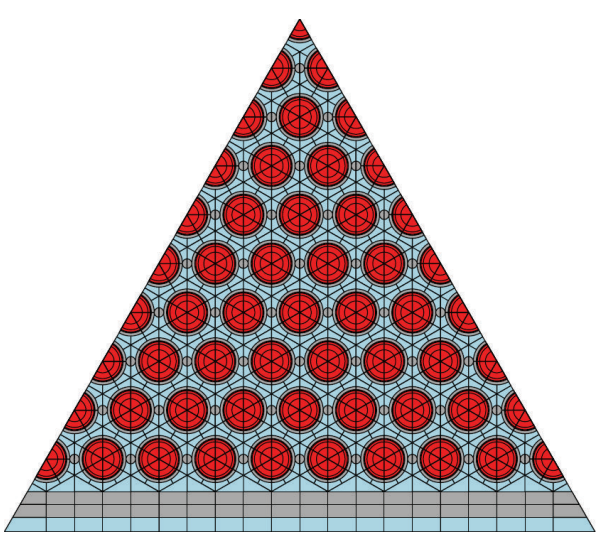

FIGURE 1: 1/6 of the reference fuel element geometry corresponding EFR.

vector is following the same basic definitions as described for the $\mathrm{Pu}$ vector mentioned previously. This definition gives $62 \%$ Am-241 and 38\% Am-243. The data for the used moderators $\mathrm{ZrH1} .6$ and $\mathrm{YH}$ is taken from [18].

\section{System with Moderating Material}

The basic idea to shift a small portion of the neutron spectrum to lower energies is achieved by the introduction of moderating material inside the wire wrapper as is shown in Figure 2. For the visualization purpose, only one unit cell is extracted from the calculated 1/6 of a fuel assembly. The purpose of the moderating material is to force up the absolute value of the negative fuel temperature feedback and to reduce of the positive coolant feedback (consisting of coolant density and temperature effect) coinciding with a reduction of the sodium void effect. The fine distributed placing of the moderating material in each unit cell offers the possibility to keep the original fuel assembly design as well as the power density and the uniform power distribution typical for a homogeneous fast reactor fuel assembly. These three facts ensure that the flow conditions in the fuel assembly can be kept like in the reference design. Thus the flow conditions can still be optimized to keep or improve the safety-related coolability.

The proposed moderating material hydrogen can be inserted in the form of stable metal-hydrogen compounds like zirconium hydride or yttrium hydride; the latter is preferable due to the higher thermal stability. For the manufacturing, it is more suitable to hydride the already produced wire, since it is much easier to handle. Hydride alloys provide a range of hydrogen concentrations in combination with considerable variation in nuclear and mechanical properties. Thus the hydrogen content can be adapted to the special requests. This makes the amount of hydrogen addition into the fuel assembly very flexible; only the maximal values are limited due to the deterioration of the material performance and the solubility limits which decrease with increasing temperatures. "It should not be inferred that the presence of hydrogen in metals is always deleterious. When present 


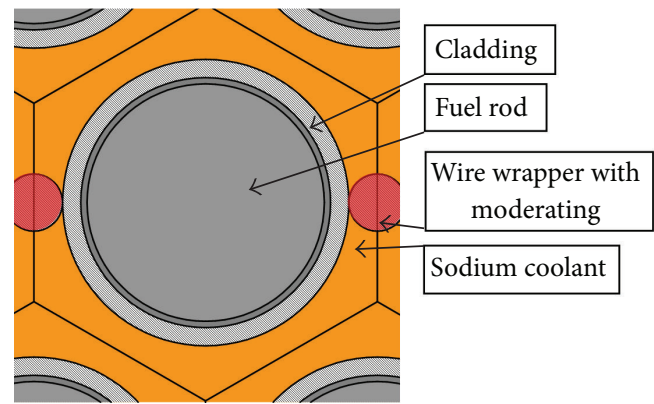

Figure 2: Unit cell out of a fuel element based on the European fast reactor (EFR) design with introduced moderation layer.

in amounts less than necessary for embrittlement, hydrogen can cause a noticeable increase in strength so long it can be retained in solution. The important point, again, is that hydrogen presents serious problems only when it is not retained in solution or when its concentration exceeds the solubility limits of the alloy so that hydride precipitates or segregation can occur. Otherwise, hydrogen reacts similarly to other alloying elements in most respects" [18].

Figure 3 gives a general overview on the changes in the neutron flux spectrum due to the insertion of moderating material compared to the reference neutron spectrum. The 190 group HELIOS library is used for these spectral curves to get a sufficiently fine resolution in the thermal groups. The figure shows a significant difference in energy distribution of the neutron flux after the insertion of the moderating material. In the case with the zirconium hydride as wire wrapper, a comparably strong low-energy tail is formed due to the strong moderation effect of the hydrogen atoms in the metallic compound. This low-energy tail has to be seen in conjunction with the radiative capture cross section of $\mathrm{U}$ 238 which is added to the figure in green. The insertion of hydrogen causes a significant increase of the share of neutrons in the energies where major capture resonances for the $\mathrm{U}$ 238 isotopes appear, especially at energies around $6.67502 \mathrm{eV}$, $20.8715 \mathrm{eV}, 36.6821 \mathrm{eV}, 66.0312 \mathrm{eV}, 102.559 \mathrm{eV}$, and $116.8923 \mathrm{eV}$. Further on, the effectiveness of moderation for the creation of the low-energy tail is compared for a compound based on zirconium and a compound based on yttrium. Both compounds contain exactly the identical amount of hydrogen.

The assembly burnup distribution after $100 \mathrm{GWd} / \mathrm{tHM}$ for the reference case and the case with the moderator inside the wire wrapper is given in Figure 4 and compared to the old fashioned solution suggesting pin containing the moderating material. The burnup in the reference fuel assembly (Figure $4(\mathrm{a}))$ is characterized by a very flat distribution $(\sim 1 \%$ difference between minimum and maximum) over the fuel assembly as well as over the fuel rods. The reason for this flat burnup distribution can be found in the flat power and neutron flux distribution and in the comparably low total cross sections at the dominating neutron energies. The flat power distribution in the fuel assembly is very favorable, since it disburdens the heat removal. The flat power distribution results in a uniform heat up of the sodium coolant. No hot

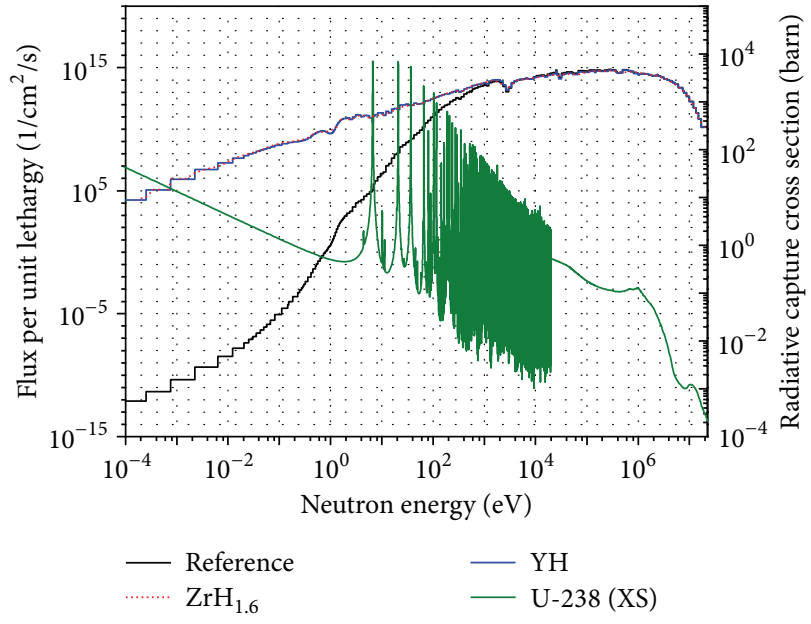

FIGURE 3: Neutron spectrum for the reference fuel assembly and for the fuel assemblies with moderating material based on different hydrogen carrying materials calculated with the 190 group library of HELIOS 1.9.

spots are created and thus all fuel rods can be operated close to the limit power and until the limit burnup defined in the operating permission.

The burnup distribution for case with fine distributed moderating material (Figure 4(b)) is rather uniform over the fuel assembly, too. A small rim effect appears due to the resonance self-shielding in the U-238 and the increased number of neutrons in the resonance region of the U-238 due to the use of the moderating material (compare Figure 3). A very limited burnup increase occurs at the pins close to the can wall. Nevertheless, the insertion of the moderating material in fine distribution, in layers, and in the wire wrapper does not create any severe deterioration in the power and burnup distribution in the fuel assembly. The evaluation of the pinwise values indicates even a more flat distribution than for the reference case, since the power and burnup at the periphery of the fuel assembly are slightly increased [10]. Only the burnup distribution inside the pin is slightly worsened due to the increased rim effect. This behavior is in strong contrast to the results for the use of moderating material in pins as discussed in several publications [18-20]. A locally concentrated introduction of moderating material like moderator pins causes a significant power and burnup increase in the pins around the moderator pins and a lower burnup in the pins far from the moderator pins (see Figure 4(c)). This uneven power and burnup distributions cause limitations to the obtainable maximal average burnup of the fuel assembly, since comparably low burnt fuel rods appear in areas far from the moderation pins. Additionally, a very strong power increase and a rim effect with all followup problems like hot spots and fuel pellet irritations due to the high burnup appear at the pins next to the moderating pins $[10,11]$.

The use of fine distributed moderating material offers the possibility to enhance the safety characteristics without changing the major operational and design parameters. 


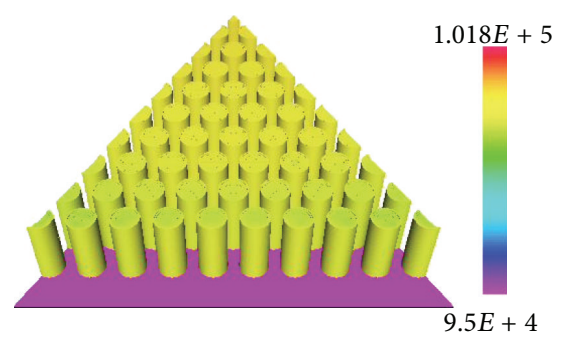

(a)

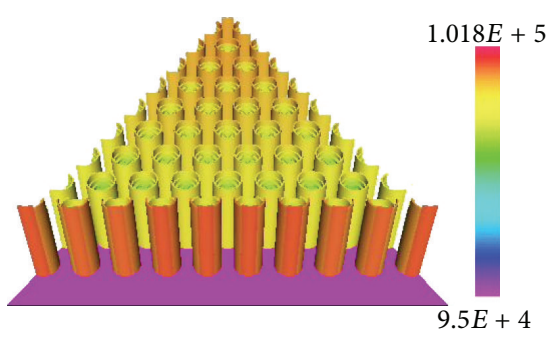

(b)

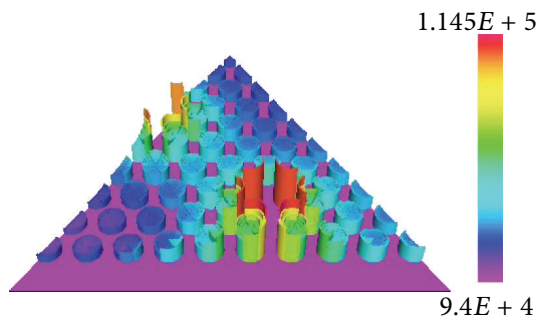

(c)

FIGURE 4: Burnup distribution at $100 \mathrm{GWd} / \mathrm{tHM}$ for the reference case (a), the case with the moderating material in the wire wrapper (b), and the case with moderating material arranged in pins (c).

Power density and distribution, fuel configuration and density, fuel assembly geometry, and coolant streaming paths are not changed at all. Only the fissile enrichment has to be increased due to the slightly reduced volume available for the fuel, and the loss of criticality caused by the moderating material has to be compensated.

The idea offers new degrees of freedom for the optimization of the design of the sodium cooled fast reactor core, the cycle strategies, and the transmutation potential. The fine distributed moderating material increases the inherent system stability significantly by reducing the positive feedback effects and enhancing the negative ones. Thus it reduces the probability of reaching sodium voiding in a transient. The interesting point is the possibility of tailoring the feedback coefficients to an ideal value simply by adapting the hydrogen content in the compound. The ideal amount has to be determined from system-specific transient and accident analysis, since strong negative feedback is not desired in all accidental scenarios.

On the suggested moderating materials some comments have to be given. For $\mathrm{ZrH}$, on the one hand, the material is a very efficient moderator, due to the extremely high slowing down power of $1.54\left(\mathrm{ZrH}_{1.94}\right)$, a value in the same range as for light water [18]. On the other hand, zirconium hydride of $\delta$ or $\varepsilon$ phases does not change the associated volume up to well above $1000^{\circ} \mathrm{C}$, since these phases are in the single phase region [18]. Thus zirconium hydride does not show the unpleasant swelling behavior of UZrH fuel, which Olander et al. describe as swelling due to void formation around the uranium particles and due to fission gas production [21]. These described processes should not appear in pure zirconium hydride moderator, since both effects are in conjunction with the Uranium component. The equilibrium hydrogen pressure in $\mathrm{ZrH}$ increases at high temperatures, especially above $900^{\circ} \mathrm{C}$; this is above the sodium voiding temperature [18]. To suppress Hydrogen release, Mueller et al. suggest to use Kanigen nickel which shows promise as a barrier coating for zirconium hydride with low hydrogen content on the basis of hydrogen loss for times up to $100 \mathrm{~h}$ at $1300^{\circ} \mathrm{F}$ in argon [18].

For YH, the slowing down power is comparable, but the thermal stability is significantly higher, up to $\sim 1300^{\circ} \mathrm{C}$ for yttrium-mono-hydride [18]. Some limited, but very positive, operational experience on the material is available too, since YH has been used in a test assembly for tailoring the neutron spectrum for tests for possible radioisotope production in the FFTF [22].

For the verification of the very significant results of the influence of moderating material on the feedback effects in general, a basic cross comparison with MCNP for the fuel temperature and moderator effect on $k_{\text {inf }}$ has been performed on simplified basis of a unit cell for the reference cases at the beginning of the investigation of the influence of fine distributed moderating materials in SFR cores to assure that the HELIOS results are reliable. Very good agreement for the moderator temperature and density and for the fuel temperature change has been achieved. The deviation between the MCNP perturbation calculation and the HELIOS 1.9 calculation of the coolant effect on $k_{\text {inf }}$ was $\sim 2 \mathrm{pcm}$ which indicates that the sodium void effect calculations are reliable too $[8,9]$.

An investigation of the transferability of the reduction of the sodium void effect from the infinite to the finite system has been carried out based on the basis of an EFR-like core configuration [23]. To avoid any irritations created by group condensation, the same number of groups has been used in DYN3D. The full core calculations have been performed with the nodal code DYN3D $[24,25]$. The calculation is based on 47 energy group cross-section sets calculated with HELIOS 1.10 using the given geometry models (compare Figure 1). To avoid any irritations created by group condensation, the same number of groups has been used in DYN3D. The full core calculations have shown that the full gain in sodium void reduction demonstrated in the infinite system can be expected to be reached in the finite system too [8]. Thus, a superposition of the findings in the infinite system and the traditional methods for the sodium void reduction like the pancake core shape or a sodium plenum is possible. Additionally, it has to be mentioned that the influence of sodium void reduction inside the fuel assembly using fine distributed moderating material already comes into action when the first sodium bubble appears. In contrast, the traditional methods to reduce the sodium void by increasing the neutron leakage do not have influence until a significant amount of sodium is voided.

\section{Consequences on Minor Actinide Transmutation}

Figure 5 shows the influence of an insertion of the minor actinides as well as the moderating material on the infinite 


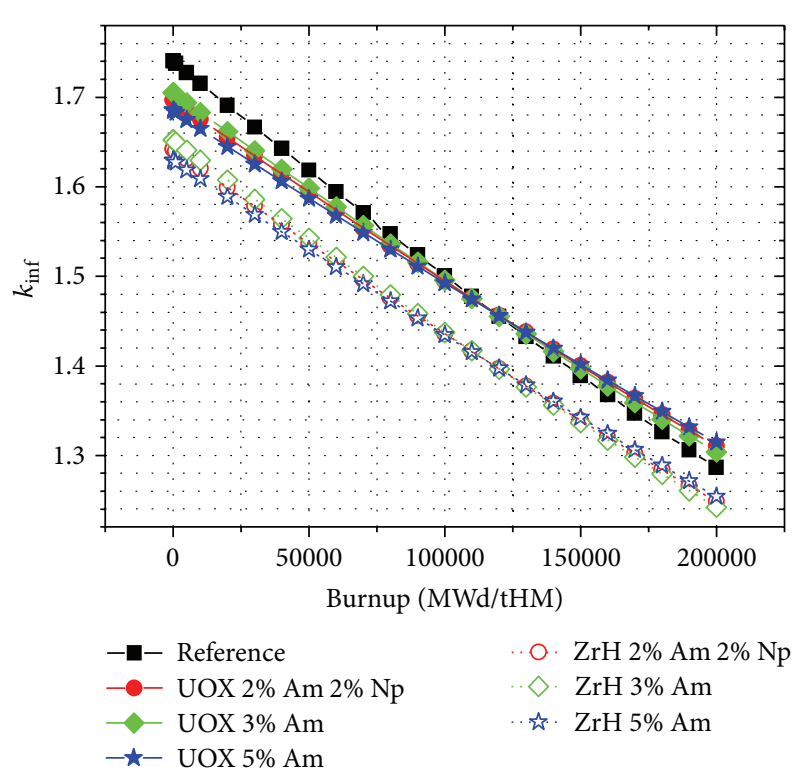

FIGURE 5: Change in the infinite multiplication factor over the burnup for the three different material configurations.

multiplication factor of a fuel assembly over burnup. Three different effects are appearing. On the one hand, the insertion of minor actinides decreases the initial $k_{\text {inf }}$ of the fuel assembly, since they cause increased neutron absorption. On the other hand, the insertion of the minor actinides reduces the loss of criticality over burnup, due to the change in the fertile material configuration caused by adding minor actinides as efficient fertile material, replacing the corresponding amount of U-238. The insertion of the moderating material ( $\mathrm{ZrH1} .6$ ) causes in all cases a reduction in the $k_{\text {inf }}$ throughout the whole observed burnup period. This reduction of the multiplication factor reduces the possible cycle time. A comparable effect appears for all other, "traditional" methods leading to sodium void reduction too, since they are based on increased neutron leakage. Thus, the breeding is reduced due to the reduced number of available excess neutrons.

The transmutation of Np-237 is shown in Figure 6 over the burnup of the reference fuel assembly. The nuclide density of Np-237 is reduced in both cases, without moderating material as well as with moderating material. In contrast to the reduction of $\mathrm{Np}-237$, in the reference case, a very small amount of Np-237 is formed. The burning of $\mathrm{Np}$ 237 in the case with a given begin of life (BOL) Np-237 concentration and the built-up of Np-237 when there is no initial concentration would lead to a comparable asymptotic value for infinitely high burnup. It is visible that the use of the distributed moderating material even enhances the transmutation of Np-237 slightly.

Figure 7 shows the Americium transmutation over burnup for the isotope Am-241 (a) and for Am-243 (b). The Am241 content in the reference case starts with a finite value, since the defined MOX fuel contains a small fraction of Am241 as long as $\mathrm{Pu}-241$ appears. The Am-241 is a decay product of $\mathrm{Pu}-241$ and appears already after short storage time of

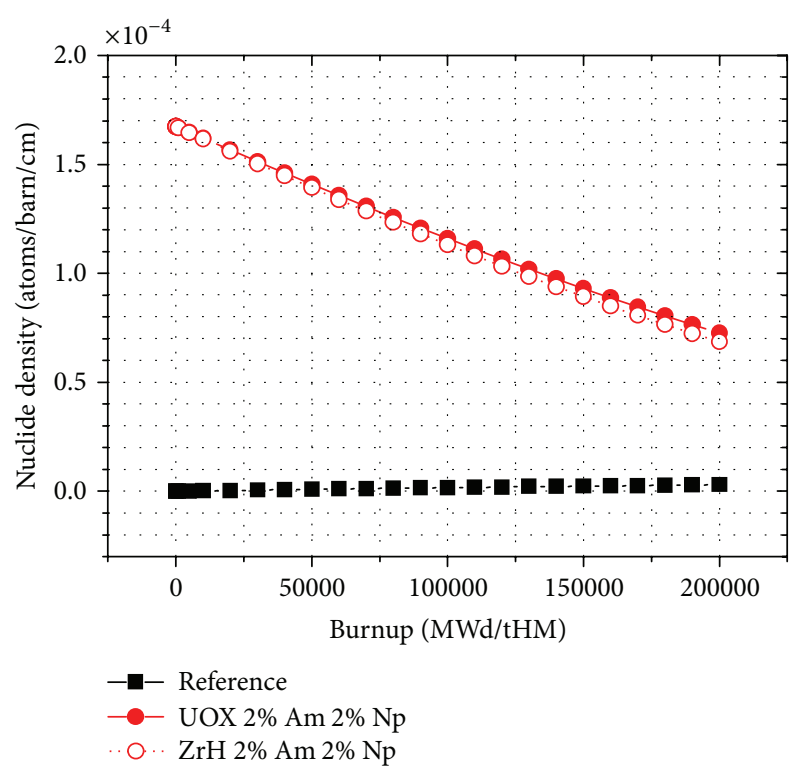

Figure 6: Change in the Neptunium-237 content over burnup for the case with and without moderation.

the separated plutonium used for the production of MOX fuel due to the short half-life of Pu-241 (14 years). In the reference case (full black squares), the initial concentration of Am-241 rises slowly to a maximum around $100 \mathrm{GWd} / \mathrm{tHM}$ and decreases after this maximum slightly. In all three cases with an added, higher initial Am-241 content, Am-241 is transmuted. The more efficient the transmutation is, the higher the initial Am-241 content is. An interesting fact is the slightly more efficient transmutation in the cases with distributed moderating material, even with the appearing slightly softer neutron spectrum (see Figure 3 ). This result is very surprising and it has to be investigated, if there is really more Am-241 burnt, or if the Am-241 is only shifted to the higher element Curium due to absorption processes. All cases, independently of the initial concentration of Am241, tend to a comparable asymptotic limit for infinite burnup. The transmutation of Am-243 shows a comparable behavior (Figure 7(b)). No Am-243 is in the BOL fuel composition in the reference case; thus there is only the production which occurs during the burnup. In all cases with a BOL Am243 content higher than $0.75 \%(\stackrel{\wedge}{=} \%$ Am content $)$ Am -243 is reduced. The Am-243 transmutation is not significantly influenced by the use of distributed moderating material.

The change in the Curium content during burnup in the minor actinide containing fuel is shown in Figure 8. The Curium isotopes are built up from Americium in all fuel configurations by neutron capture and decay processes. The Cm-242 content (Figure 8(a)) rises in all cases in dependence of the initial Am-241 content to a maximum value. The more the Am-241 is available, the more the Cm-242 is built in the initial phase, but with decreasing Am-241 content, the Cm-242 content starts to be reduced too after reaching the maximum at about $100 \mathrm{GWd} / \mathrm{tHM}$. The insertion of the moderating material leads in all cases to a slightly increased 


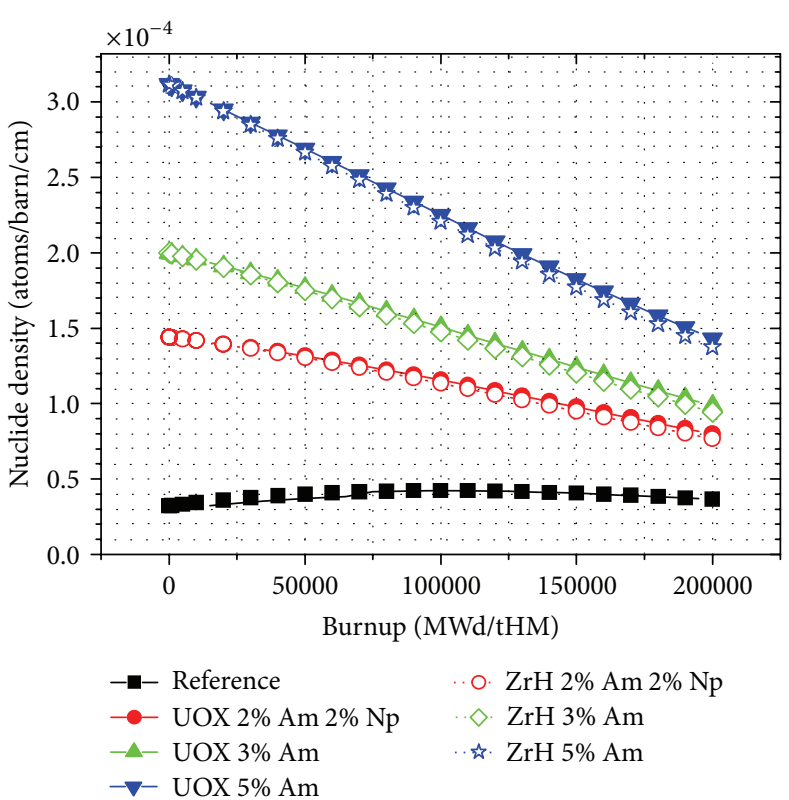

(a)

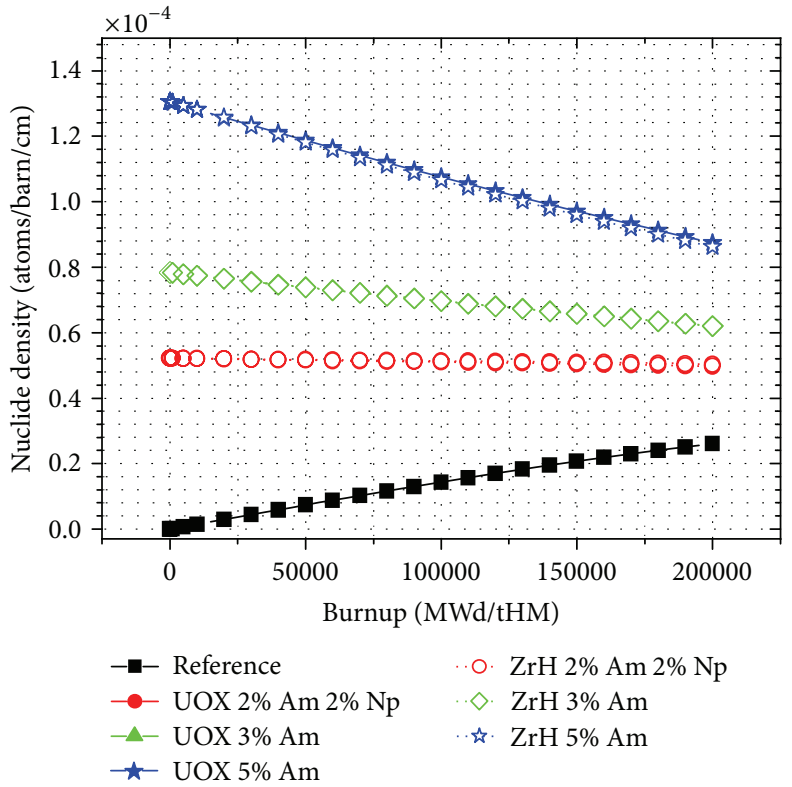

(b)

Figure 7: Change in the Americium-241 (a) and the Americium-243 (b) content over burnup for the case with and without moderation.

built-up and a slightly higher EOL concentration of Cm242. The case with the highest Am content (5\%) leads after reaching a maximum at $\sim 100 \mathrm{GWd} / \mathrm{tHM}$ already to a significant reduction of the Cm-242 content. The Cm-244 content (Figure 8(b)) rises for all cases over the full observed burnup period. The overall Cm-244 content is strongly dependent on the initial Americium content in the fuel. The Cm-244 accumulation is slightly higher for all cases with moderating material.

A more detailed insight into the influence of the fine distributed moderating material on transmutation is given in Tables 1 and 2. The comparison of the transmutation efficiency provides information on which fuel assembly provides a lower content of minor actinides at the end of life (EOL). A positive value indicates an advantageous behavior of the fuel assembly with moderating material; a negative value indicates a better transmutation performance for the assembly without moderating material. The comparison of the transmutation efficiency (see Table 1)

Transmutation efficiency [\%]

$=\left(1-\frac{\text { isotope number density with moderating material }}{\text { isotope number density without moderating material }}\right)$

$\cdot 100$

shows that the Am-241 transmutation is roughly 4\% more efficient in the fuel assemblies with moderating material for all configurations of transmutation fuel. The Transmutation of Am-243 is slightly less efficient $(-1.28 \%)$ for a low Americium content and slightly more efficient (1.42\%) for high Americium content. In the cases with moderating material, $\sim 2.5 \%$ more $\mathrm{Cm}-242$ is produced than that in the reference cases without moderating material. The use of moderating material increases the production of $\mathrm{Cm}-244$ by 7 to $9 \%$. The transmutation of Np-239 is more efficient in the fuel assembly with moderating material. $5.5 \%$ more $\mathrm{Np}-239$ is burnt than in the reference case.

The detailed comparison of the differences in the number densities

Transm. efficiency [number density]

= isotope number density with moderating material

- isotope number density without moderating material

is given in the lower part of Table 1. A positive number indicates more efficient transmutation in the assembly with moderating material and a negative number more efficient transmutation in the assembly without moderating material. A detailed comparison of the numbers shows that the amount of the Am-241 reduction is higher than the increase in the number densities of the higher isotopes (Am-243, Cm-242, $\mathrm{Cm}-244)$ in all cases with moderating material. Thus there is really more Am-241 burnt in the fuel assemblies with fine distributed material than that in the "clean" transmutation fuel assemblies. The effect rises with increasing Americium concentration at BOL. Over all it can be stated that the insertion of the fine distributed moderating material in the wire wrapper does at least not have a negative influence on the transmutation efficiency. 


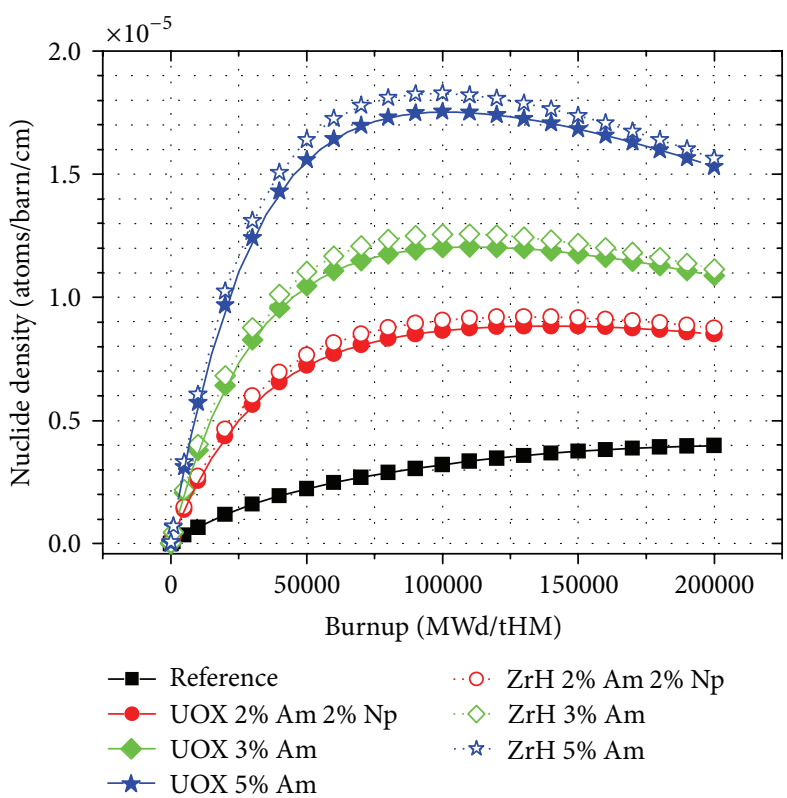

(a)

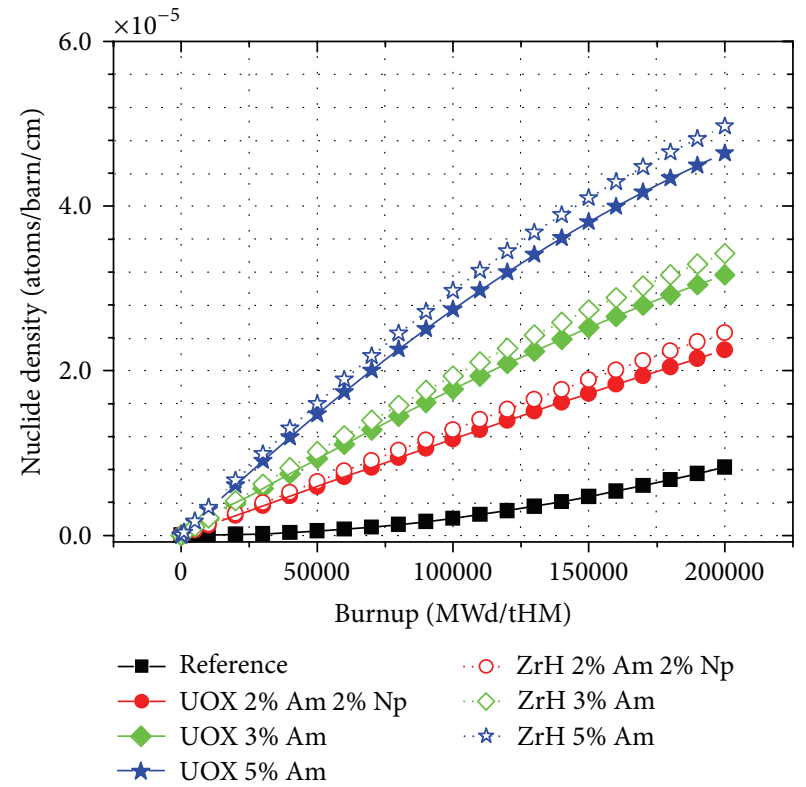

(b)

FIgURE 8: Change in the Curium-242 (a) and the Curium-244 (b) content over burnup for the case with and without moderation.

TABLE 1: Comparison of the transmutation efficiency between the reference cases without and the cases with moderating material for the different transmutation fuels.

\begin{tabular}{|c|c|c|c|c|c|}
\hline Transmutation eff. (comparison) & Am-241 & Am-243 & $\mathrm{Cm}-242$ & $\mathrm{Cm}-244$ & Np-239 \\
\hline $2 \% \mathrm{~Np} 2 \%$ Am EOL & $3.87 \%$ & $-1.28 \%$ & $-2.68 \%$ & $-9.18 \%$ & $5.65 \%$ \\
\hline $3 \% \mathrm{Am} \mathrm{EOL}$ & $4.27 \%$ & $0.02 \%$ & $-2.43 \%$ & $-8.24 \%$ & \\
\hline $5 \%$ Am EOL & $4.04 \%$ & $1.42 \%$ & $-2.15 \%$ & $-7.05 \%$ & \\
\hline 8\% Am EOL & $3.59 \%$ & $2.20 \%$ & $-1.93 \%$ & $-6.30 \%$ & \\
\hline $2 \% \mathrm{~Np} 2 \% \mathrm{Am} \mathrm{EOL}$ & $-2.9466 E-06$ & $6.0580 E-07$ & $2.1653 E-07$ & $2.0270 E-06$ & $-3.9219 E-06$ \\
\hline 3\% Am EOL & $-4.2160 E-06$ & $-1.4000 E-08$ & $2.6400 E-07$ & $2.6060 E-06$ & \\
\hline 5\% Am EOL & $-5.7900 E-06$ & $-1.2410 E-06$ & $3.2900 E-07$ & $3.2740 E-06$ & \\
\hline 8\% Am EOL & $-7.6950 E-06$ & $-2.8100 E-06$ & $4.1970 E-07$ & $4.2524 E-06$ & \\
\hline
\end{tabular}

The analysis of the Americium and Neptunium transmutation rate is given in Table 2 . Consider

Transmutation rate [\%]

$$
=\left(1-\frac{\text { isotope number density at EOL }}{\text { isotope number density at BOL }}\right) \cdot 100 \text {. }
$$

The transmutation rate provides the information on how much of the initially inserted material is transmuted at the end of the lifetime of the fuel assembly. A higher number indicates a better transmutation performance for the corresponding isotope. After a burnup of $200 \mathrm{GWd} / \mathrm{tHM}$, the Am241 concentration is roughly halved and the transmutation rate is increased with increasing initial Americium content. The transmutation of Am-243 becomes only efficient for high Americium content, at least 3\% even better 5\%. The transmutation of $\mathrm{Np}-237$ remains nearly constant at a low content of $2 \%$ efficient.
The conclusion of this evaluation of the transmutation rate is that transmutation especially of Americium becomes significantly more efficient with increasing initial Americium content. Unfortunately, the permissible Americium content is limited due to the negative influence of the Americium on the feedback effects in the reactor core and due to the negative influence on the fuel behavior caused by the high fission gas release in Americium containing fuel.

The consequence of the insertion of minor actinides on different feedback effects and other safety-related values is given in Table 3. A positive value in the negative Doppler feedback indicates the desired stronger feedback. For the positive coolant effect and void effect, a positive value is desired, since the positive feedback should be reduced to stabilize the reactor. The absorber worth reflects the negative reactivity which is inserted by the addition of a given amount of absorbing material; a value close to zero indicates an unchanged efficiency of the absorber rods; a negative value signs a demand of a higher number of absorber rods; a 
TABLE 2: Comparison of the transmutation rate for the reference cases and the cases with moderating material for the different transmutation fuels.

\begin{tabular}{cccccc}
\hline Transmutation rate & & Reference & \multicolumn{3}{c}{ With moderator } \\
& Am-241 & Am-243 & Np-237 & Am-241 & Am-243 \\
\hline 2\% Np 2\% Am EOL & $-47.0 \%$ & $-9.1 \%$ & $-58.5 \%$ & $-49.1 \%$ & $-8.0 \%$ \\
3\% Am EOL & $-50.6 \%$ & $-20.8 \%$ & & $-52.7 \%$ & $-20.8 \%$ \\
$5 \%$ Am EOL & $-54.1 \%$ & $-33.0 \%$ & $-55.9 \%$ & $-34.0 \%$ \\
$\mathbf{8} \%$ Am EOL & $-\mathbf{5 5 . 3 \%}$ & $-\mathbf{3 8 . 9 \%}$ & & $-\mathbf{5 6 . 9 \%}$ & $-\mathbf{4 0 . 2 \%}$ \\
\hline
\end{tabular}

TABLE 3: Feedback effects and absorber worth for the cases with different transmutation fuels.

\begin{tabular}{|c|c|c|c|c|c|c|c|c|}
\hline & $\begin{array}{c}\text { UMOX } \\
\text { 2\% Am } 2 \% \text { Np }\end{array}$ & $\begin{array}{c}+\mathrm{ZrH} \\
2 \% \mathrm{Am} 2 \% \mathrm{~Np}\end{array}$ & $\begin{array}{l}\text { UMOX } \\
3 \% \text { Am }\end{array}$ & $\begin{array}{c}+\mathrm{ZrH} \\
3 \% \mathrm{Am}\end{array}$ & $\begin{array}{l}\text { UMOX } \\
5 \% \text { Am }\end{array}$ & $\begin{array}{c}+\mathrm{ZrH} \\
5 \% \mathrm{Am}\end{array}$ & $\begin{array}{c}+\mathrm{ZrH} 8 \% \\
\text { Am }\end{array}$ & $\begin{array}{c}1.2 * \mathrm{ZrH} \\
8 \% \mathrm{Am}\end{array}$ \\
\hline \multicolumn{9}{|c|}{ Doppler effect $T_{f}+100 \mathrm{~K}$} \\
\hline BOL & $-30.2 \%$ & $59.7 \%$ & $-23.0 \%$ & $73.8 \%$ & $-36.4 \%$ & $49.4 \%$ & $18.9 \%$ & $31.9 \%$ \\
\hline EOL & $-26.9 \%$ & $52.2 \%$ & $-20.2 \%$ & $65.2 \%$ & $-30.9 \%$ & $46.8 \%$ & $18.7 \%$ & $32.3 \%$ \\
\hline \multicolumn{9}{|c|}{ Coolant effect $T_{\mathrm{c}}+50 \mathrm{~K}$} \\
\hline BOL & $4.9 \%$ & $-8.1 \%$ & $5.7 \%$ & $-11.7 \%$ & $12.2 \%$ & $-4.6 \%$ & $2.1 \%$ & $-0.2 \%$ \\
\hline EOL & $0.9 \%$ & $-12.0 \%$ & $2.1 \%$ & $-11.3 \%$ & $1.2 \%$ & $-14.2 \%$ & $-13.3 \%$ & $-15.0 \%$ \\
\hline \multicolumn{9}{|c|}{ void effect } \\
\hline BOL & $9.2 \%$ & $-5.3 \%$ & $6.9 \%$ & $-8.1 \%$ & $10.7 \%$ & $-3.2 \%$ & $2.7 \%$ & $0.9 \%$ \\
\hline EOL & $-0.2 \%$ & $-11.8 \%$ & $-0.4 \%$ & $-12.5 \%$ & $-0.6 \%$ & $-12.3 \%$ & $-11.9 \%$ & $-13.9 \%$ \\
\hline \multicolumn{9}{|c|}{ Absorber rod worth } \\
\hline BOL & $-7.8 \%$ & $-3.6 \%$ & $-6.0 \%$ & $-1.6 \%$ & $-9.6 \%$ & $-5.6 \%$ & $-11.1 \%$ & $-10.6 \%$ \\
\hline EOL & $-9.5 \%$ & $-5.0 \%$ & $-6.9 \%$ & $-2.0 \%$ & $-11.1 \%$ & $-6.8 \%$ & $-13.3 \%$ & $-12.9 \%$ \\
\hline
\end{tabular}

positive value would allow reducing the number of absorber rods.

The insertion of the minor actinides into the fuel has a strong influence on the safety-related effects of the fuel assembly. The negative Doppler effect is reduced in all cases due to the influence of the minor actinides. The already positive coolant effect (the combination of the coolant temperature and the coolant density effect) becomes more positive with increasing Americium fraction. The positive sodium void effect at BOL increases compared to the reference case in all configurations and the absorber rod worth of the shutdown rods decreases compared to the reference case in all configurations, which requires more shutdown elements for the safe shutdown in hot condition compared to the reference case in all configurations. The parallel insertion of minor actinides and distributed moderating material relaxes the situation significantly. The effect of the moderating material on the Doppler effect is even strong enough to overcompensate the influence of the minor actinides in all cases; thus the Doppler effect is still significantly stronger-more negative-than in the reference case without minor actinides and moderating material. The same behavior can be observed for the coolant effect as well as for the sodium void effect. The influence of the minor actinides is overcompensated in all cases by the insertion of the fine distributed moderating material. Finally, the absorber worth, the reduction of the absorber rod worth is only partly compensated due to the insertion of the moderating material, but the situation is relaxed in all cases due to the insertion of moderating material.
One drawback of the moderating material should not be forgotten; due to the significantly stronger Doppler effect, more shutdown rods are required for reaching a defined cold subcriticality status. The amount of moderating material to be used is sure to be optimized from the point of view of system safety and transient behavior and the thermal stability of the $\mathrm{ZrH}$ moderator has to be investigated thoroughly or a more stable material like $\mathrm{YH}$ has to be envisaged.

An independent evaluation for the maximum possible amount of minor actinides in combination with the use of fine distributed moderating material closes the study. The strong influence of the minor actinides on the safety relevant feedback effects limits the possible amount of minor actinide insertion. For the given amount of hydrogen insertion, the limit has been found for $8 \%$ Americium content where the coolant feedback and the sodium void at BOL become slightly positive (see Table 3 first bold column), but this is still compensated by the enhancement of the Doppler feedback by more than $18 \%$. The consequences of this Americium content can be compensated once more by a slight increase of the hydrogen content. This is studied by a test for $8 \%$ Americium content and by a $20 \%$ increased $\mathrm{ZrH}_{1.6}$ content. The insertion of $20 \%$ more hydrogen leads once more to at least balanced or even enhanced feedbacks and thus to a more stable system (see Table 3 second bold column). From the transmutation point of view, the by $3 \%$ increased Americium amount (relative 60\% more Americium) leads to an increased Am-241 burning by $1 \%$ (relative increase 2\%) and an increased Am-243 burning by roughly 6\% (relative 
increase $\sim 18 \%$ ) (see Table 2 bold row). Thus the expected increase of transmutation efficiency can be found mainly for Am-243 which is more problematic to be transmuted.

Nevertheless, the increase of Americium content cannot be continued ad infinitum, since the acceptable Americium content is limited by the swelling behavior of transmutation fuel too. Experiments have demonstrated that target pellets containing $10-12 \mathrm{wt} \%{ }^{241} \mathrm{Am}$ already show swelling of the target pellets by the order of $15 \%$. This is attributed to accumulation of helium, produced by alpha decay of ${ }^{242} \mathrm{Cm}$ that occurs in the transmutation scheme of ${ }^{241} \mathrm{Am}$ [26].

\section{Conclusions}

The effect of the insertion of fine distributed moderating material on the feedback effects and the void effect in a sodium cooled fast reactor has been investigated in several publications [8-11]. The strong improvement in the fuel temperature and coolant feedback effect and in the sodium void effect has already been demonstrated, but negative consequences to the transmutation efficiency have been assumed due to the softer neutron spectrum.

The effect of fine distributed moderating material on fuel assemblies with a high minor actinide concentration like those foreseen for minor actinide transmutation has been investigated for 3 different fuel compositions: fuel with $2 \% \mathrm{~Np}$ and $2 \% \mathrm{Am}$, fuel with $3 \% \mathrm{Am}$, and fuel with $5 \%$ Am. It is demonstrated that the influence of the minor actinides on the feedback effects can be easily compensated by the insertion of fine distributed moderating material into the wire wrapper. The investigation of the transmutation efficiency has shown that there is only a very limited influence due to the moderating material. On the one hand, the Americium transmutation rate is even slightly higher for the fuel assembly containing moderating material. On the other hand, the Curium production increases slightly. Nevertheless, a detailed comparison of the data shows that the higher Americium efficiency rate is not only because breeding reactions lead to more Curium but also a higher fission rate of Americium is reached. Further, it is shown that the Americium transmutation rate depends strongly on the initial Americium amount in the fuel assembly.

Using fine distributed moderating materials, for example, inside the wire wrapper has the potential to improve the safety of a dedicated core for minor actinide transmutation. Additionally, it is shown that the transmutation rate can be improved since it is possible to increase the BOL amount of minor actinides in the core. This can be reached, since it is possible to eliminate the negative effect of the minor actinides on core stability and transient behaviour up to an Americium content of $\sim 8 \%$. Additionally, it is shown that an increase of the hydrogen content by $20 \%$ can even improve all feedback effects in this case with $8 \%$ Americium content. Using this configuration allows a relative increase of the Am-243 transmutation rate by nearly $20 \%$ which is an important improvement for an isotope which is hard to transmute. Thus the concept of fine distributed moderating material offers the possibility of increased transmutation efficiency in conjunction with an elimination of the negative consequences of transmutation fuel.

The use of fine distributed moderating material can influence the safety of fast reactors strongly-it opens the stage for designable feedback coefficients; thus it creates a new degree of freedom for the optimization of important inherent safety-related parameters in the design of sodium-cooled fast reactor cores.

\section{References}

[1] "IAEA TM on Innovative Fast Reactor Designs with Enhanced Negative Reactivity Feedback Features," IAEA Headquarters, Vienna, Austria, 2012, accessed March 11, 2013, http://www.iaea .org/NuclearPower/Meetings/2012/2012-02-27-02-29-TMNPTD.html.

[2] H. Hummel and D. Okrent, Reactivity Coefficients in Large Fast Power Reactors, ANS, 1970.

[3] R. N. Hill and H. Khalil, "Evaluation of LMR design options for reduction of sodium void worth," in Proceedings of International Conference on the Physics of Reactors, vol. 1, pp. 11-19, Marseille, France, 1980

[4] G. Rimpault, L. Buiron, P. Sciora, and F. Varaine, "Towards GEN IV SFR design: promising ideas for large advanced SFR core designs," in International Conference on the Physics of Reactors (PHYSOR '08), pp. 2394-2400, Interlaken, Switzerland, September 2008.

[5] B. Carluec and P. L. Pinto, "Lessons learned from Fushima accident as regards the safety approach of the ASTRID project at conceptual design stage," in Proceedings of the IAEA Technical Meeting on Impact of the Fukushima Event on Current and Future Fast Reactor Design, Helmholtz-Zentrum DresdenRossendorf, Dresden, Germany, March 2012, accessed March 11, 2013, http://www.iaea.org/NuclearPower/Meetings/2012/201203-19-03-23-TM-NPTD.html.

[6] L. Buiron et al., "Innovative core design for generation IV sodium-cooled fast reactors," in Proceedings of the International Congress on Advances in Nuclear Power Plants (ICAPP '10), Nice, France, 2007.

[7] K. Sun et al., "Void reactivity decomposition for the sodium coold fast reactor in equilibrium closed fuel cycle," in Proceedings of the Advances in Reactor Physics to Power the Nuclear Renaissance (PHYSOR '10), Pittsburgh, Pa, USA, 2010.

[8] B. Merk, E. Fridman, and F. P. Weiß, "On the use of zirconium based moderators to enhance the feedback coefficients in a MOX fuelled sodium cooled fast reactor," Nuclear Science and Engineering, vol. 171, 2, pp. 136-149, 2012.

[9] B. Merk, E. Fridman, and F. P. Weiß, "On the use of a moderation layer to improve the safety behavior in sodium cooled fast reactors," Annals of Nuclear Energy, vol. 38, no. 5, pp. 921-929, 2011.

[10] B. Merk and F. P. Weiß, "Analysis of the influence of different arrangements for $\mathrm{ZrH}$ moderator material on the performance of a SFR core," Annals of Nuclear Energy, vol. 38, pp. 2374-2385, 2011.

[11] B. Merk and F. P. Weiß, "On the effect of different placing $\mathrm{ZrH}$ moderator material on the performance of a SFR core," in Advances in Reactor Physics-Linking Research, Industry, and Education (PHYSOR '12), Knoxville, Tenn, USA, 2012.

[12] E. A. Villarino, R. J. J. Stammler, A. A. Ferri, and J. J. Casal, "HELIOS: angularly dependent collision probabilities," Nuclear Science and Engineering, vol. 112, pp. 16-31, 1992. 
[13] R. Sanchez et al., "APOLLO II: a user-oriented, portable, modular code for multigroup transport assembly calculations," Nuclear Science and Engineering, vol. 100, article 352, 1988.

[14] IAEA Fast Reactor Database, 2006, http://www.iaea.org/inisnkm/nkm/aws/frdb/auxiliary/generalInformation.html.

[15] A. E. Waltar and A. B. Reynolds, Fast Breeder Reactors, Pergamon Press, New York, NY, USA, 1981.

[16] A. Pay, E. Francillon, B. Steinmetz, D. Barnes, and N. Meda, "European Fast Reactor (EFR) fuel element design," in Proceedings of the 10th International Conference on Structural Mechanics in Reactor Technology, Anaheim, Calif, USA, 1989, http://www.iasmirt.org/iasmirt-3/SMiRT10/DC_250515.

[17] J. Carmack and K. O. Pasamehmetoglu:, "Review of transmutation fuel studies," in INL/EXT-08-13779, or GNEP-FUEL-TDRT-2008-000050, U.S. Department of Energy, Transmutation Fuel Campaign, 2008, http://www.inl.gov/technicalpublications/Documents/3901056.pdf.

[18] W. M. Mueller, J. P. Blackledge, and G. G. Libowitz, Metal Hydrides, Academic Press, New York, NY, USA, 1968.

[19] K. Tuček, J. Carlsson, and H. Wider, "Comparison of sodium and lead-cooled fast reactors regarding reactor physics aspects, severe safety and economical issues," Nuclear Engineering and Design, vol. 236, no. 14-16, pp. 1589-1598, 2006.

[20] S. E. Bays, H. Zhang, and H. Zhao, "The industrial sodium cooled fast reactor," in ANFM, INL/CON-0915519 PREPRINT, 2009, http://www.inl.gov/technicalpublications/Documents/4363828.pdf.

[21] D. Olander, E. Greenspan, H. D. Garkisch, and B. Petrovic, "Uranium-zirconium hydride fuel properties," Nuclear Engineering and Design, vol. 239, pp. 1406-1424, 2009.

[22] D. W. Wootan, J. A. Rawlins, L. L. Carter, H. R. Brager, and R. E. Schenter, "Analysis and results of a hydrogen-moderated isotope production assembly in the fast flux test facility," Nuclear Science and Engineering, vol. 103, no. 2, pp. 150-156, 1989.

[23] J. C. Lefèvre, C. H. Mitchell, and G. Hubert:, "European fast reactor design," Nuclear Engineering and Design, vol. 162, pp. 133-143, 1996.

[24] U. Rohde, U. Grundmann, and S. Kliem, "DYN3D - advanced reactor simulations in 3D," Nuclear Energy Review, vol. 2, pp. 28-30, 2007.

[25] C. Beckert and U. Grundmann, "A nodal expansion method for solving the multigroup SP3 equations in the reactor code DYN3D," in Proceedings of the Joint International Topical Meeting on Mathematics and Computations and Supercomputing in Nuclear Applications (M\&C+SNA '07), Monterey, Calif, USA, April 2007.

[26] R. J. M. Konings et al., "The EFTTRA-T4 experiment on americium transmutation," Journal of Nuclear Materials, vol. 282, no. 2-3, pp. 159-170, 2000. 


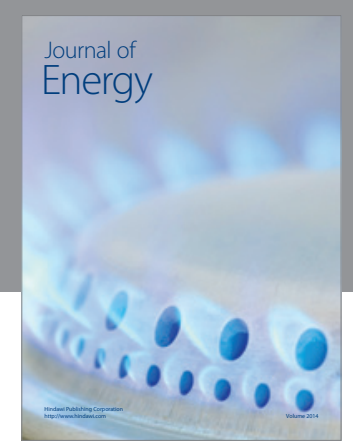

Journal of

Industrial Engineering
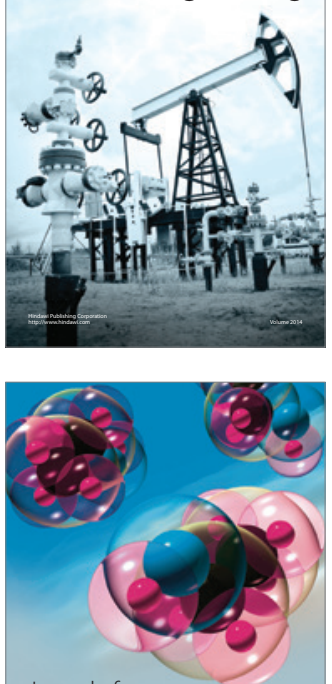

Fuels
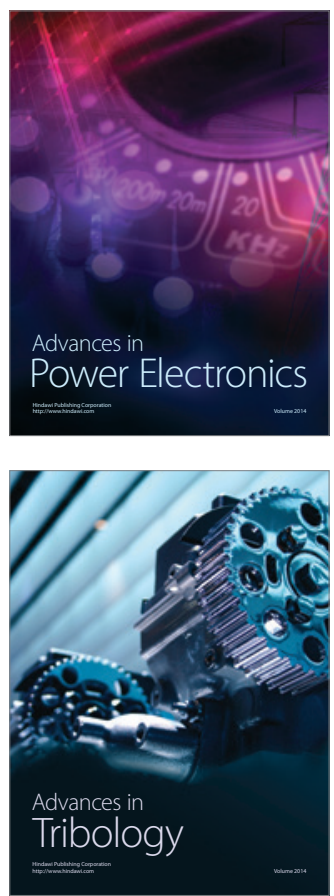

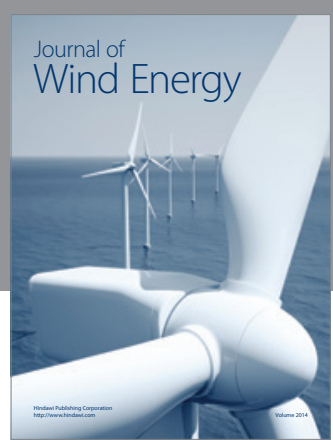

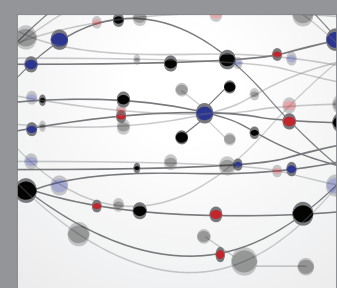

The Scientific World Journal

Submit your manuscripts at http://www.hindawi.com

Journal of

Structures
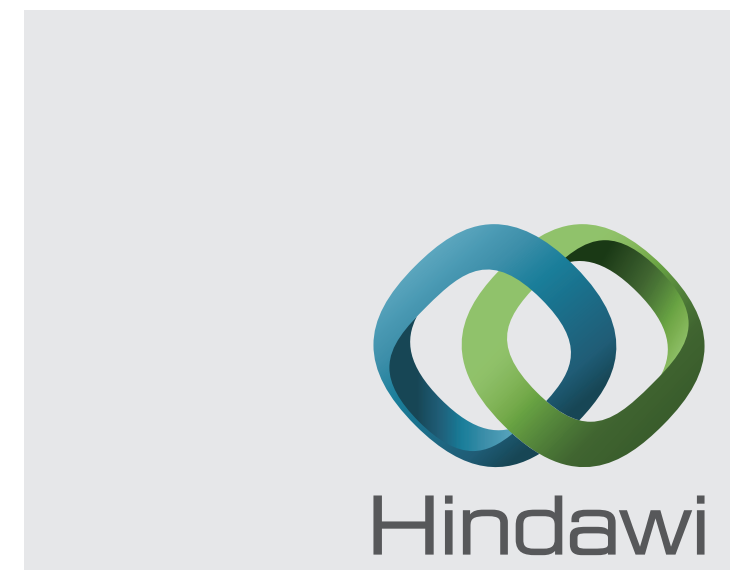

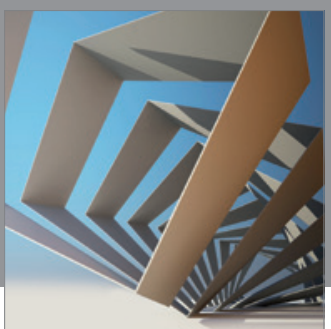

Rotating

Machinery
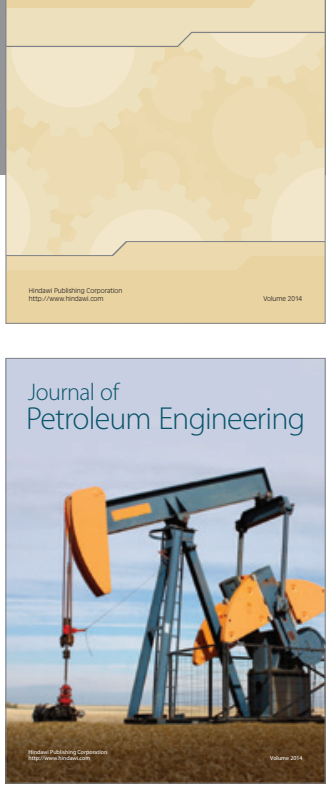

Journal of

Solar Energy
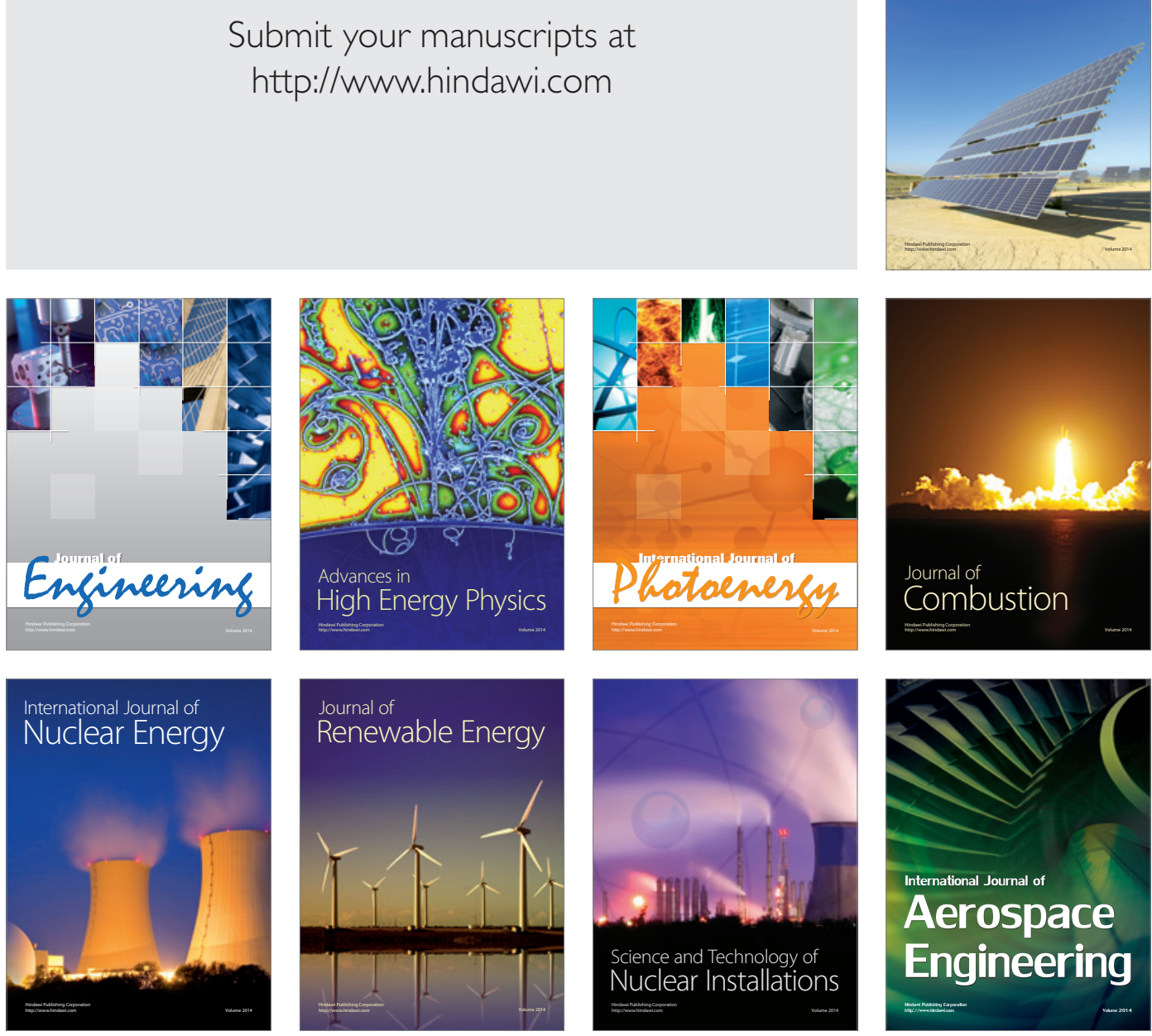